\title{
O problema do complemento circunstancial e a oração subordinada adverbial em espanhol
}

\section{The problem of circumstantial complements and adverbial subordinate clauses in Spanish}

\author{
Shirley de Sousa Pereira*
}

\begin{abstract}
RESUMO: Neste trabalho faremos uma breve revisão teórica acerca da problemática classificação do complemento circunstancial na gramática tradicional espanhola, na qual discutiremos a sua suposta identidade funcional com o complemento adverbial, assim como o seu caráter marginal no predicado verbal (ALARCOS LLORACH, 1970; ROJO, 1990). Discutiremos sobre a viabilidade das propostas de Álvarez Martínez (1992) e de Gutiérrez Ordóñez (2002) de incluir a categoria do advérbio ao grupo nominal dos substantivos e adjetivos e de que o complemento circunstancial pode assumir uma função nominal. Tais considerações trazem como consequência a inclusão das orações subordinadas circunstanciais e adverbiais (próprias e impróprias) no grupo das orações subordinadas substantivas.
\end{abstract}

PALAVRAS-CHAVE: complemento circunstancial; complemento adverbial; funções marginais; subordinada adverbial.

ABSTRACT: In this work we will make a brief theoretical review about the problematic classification of the circumstantial complement in traditional Spanish grammar, in which we will discuss its supposed functional identity with the adverbial complement, as well as its marginal character in the verbal predicate (ALARCOS LLORACH, 1970; ROJO, 1990). We will discuss the feasibility of the proposals of Álvarez Martínez (1992) and Gutiérrez Ordóñez (2002) of including adverbs in the nominal group of nouns and adjectives and if the circumstantial complement can assume a nominal function. Such considerations result in the inclusion of subordinate circumstantial and (proper and improper) adverbial clauses in the group of substantive subordinate clauses.

KEYWORDS: circumstantial complement; adverbial complement; marginal functions; adverbial subordinate clauses.

\footnotetext{
* Professora na Universidade Federal de Pernambuco (UFPE), doutora pela Universidade de Santiago de Compostela, shirleype@yahoo.com.br, ORCID oooo-0002-7275-0519.
} 


\section{Introdução}

No âmbito da sintaxe oracional da língua espanhola, o estudo do complemento circunstancial costuma suscitar diversos problemas devido à sua tradicional definição como uma palavra ou um grupo de palavras, geralmente identificados como advérbios ou locuções adverbiais (de tempo, lugar, companhia, modo, instrumento, causa, finalidade) que não são exigidos pelo esquema argumental do verbo e que, portanto, podem ser facilmente prescindíveis. No entanto, embora tal critério possa aplicar-se à maioria dos complementos circunstanciais de tipo locativo, alguns deles se deslocam da sua posição marginal e passam a ocupar funções centrais como em Santiago em reside en Santiago ou em la mesa em puso el libro en la mesa. Por outro lado, a averiguação de que nem todos os complementos possuem correspondência com advérbios deu origem a uma diferenciação de funções em complementos adverbiais e não adverbiais, circunstanciais e não circunstanciais que, por sua vez, ocasionou a não menos incoerente divisão entre orações subordinadas adverbiais próprias e impróprias.

À vista do exposto, apresentaremos uma breve revisão teórica acerca da problemática classificação do complemento circunstancial na gramática tradicional espanhola, na qual discutiremos a sua suposta identidade funcional com o complemento adverbial, assim como o seu caráter marginal no predicado verbal (ALARCOS LLORACH, 1970; ROJO, 1990). Discutiremos sobre a possibilidade de que a categoria do advérbio pode pertencer ao grupo nominal dos substantivos e adjetivos (ÁLVAREZ MARTÍNEZ, 1992) e de que o complemento circunstancial assume uma função nominal (GUTIÉRREZ ORDÓÑEZ, 2005) o que, consequentemente, implica na inclusão das orações subordinadas circunstanciais e adverbiais (próprias e impróprias) no grupo das orações subordinadas substantivas. 


\section{O complemento circunstancial na gramática tradicional}

Atendendo às pautas de uma longa tradição gramatical e seguindo critérios de base semântica, o termo complemento circunstancial tem sido utilizado pela imensa maioria de gramáticos da língua espanhola para classificar uma série de complementos verbais que remetem a significados de natureza bastante numerosa e heterogênea. A este propósito, Porto Dapena (apud FERNÁNDEZ LÓPEZ, 2015) chama atenção para a inadequação do termo que se emprega para denotar uma ampla e problemática lista de complementos temporais, locativos, modais, causais, finais, instrumentais etc. Nesse sentido, o autor reivindica que a definição do termo deve atender, sobretudo, a critérios formais, pois alude mais propriamente a uma função sintática e não exclusivamente semântica. Assim, considerando sua posição na estrutura oracional, dá exemplos nos quais o mesmo sintagma preposicional en el patio denota circunstância de lugar semanticamente, porém, no nível sintático, tem a função de complemento circunstancial em los niños juegan en el pátio e de suplemento em los niños se encuentran en el pátio.

Igualmente, Gómez Torrego (2002) considera insuficiente a tradicional definição semântica dada aos complementos circunstanciais na medida em que não permite uma diferenciação da função assumida por determinados segmentos na oração, conforme os exemplos:

Corta el jamón con este cuchillo.73

Este cuchillo no corta bien el jamón.

(GÓMEZ TORREGO, 2002, p. 31074)

73 Todas as traduções são da autora.

74 "Corta o presunto com esta faca. Esta faca não corta bem o presunto." 
Observa-se que esse cuchillo assume a função semântica de instrumento em ambas as orações, porém cumpre as funções sintáticas de complemento circunstancial na primeira oração e de sujeito na segunda, respectivamente.

A estreita relação entre funções sintáticas e funções semânticas atribuídas aos elementos que entram na combinatória sintagmática do predicado foi muito discutida na chamada sintaxe de dependências e, especialmente, no âmbito da gramática formal. A partir da clássica noção semântica do predicado, pressupõese que este está organizado de acordo com dois níveis sintagmáticos: um sintático e outro semântico, de modo que, paralelo à estrutura argumental, existe uma estrutura temática ou esqueleto do significado, que contém informação de cunho semântico acerca dos argumentos ou elementos selecionados pelo predicado (BOSQUE; GUTIÉRREZ-REXACH, 2009, p. 271). Ao segundo nível sintagmático ou estrutura temática correspondem as chamadas funções semânticas, que equivalem aos papéis que desempenham cada um dos participantes associados aos argumentos em um evento determinado, o que significa que os predicados são definidos pela quantidade e natureza semântica dos argumentos que requerem. Assim, por exemplo, o verbo dar em Mario (sujeito) le dio el libro (complemento direto) a su hermano (complemento indireto) possui, respectivamente, três argumentos que realizam as funções semânticas (papéis temáticos) de agente (Mario é o participante que realiza a ação), tema (el libro é o participante afetado pela ação) e destinatário (a su hermano é o participante que recebe o tema). Do mesmo modo, Luís desempenha a função sintática de sujeito e o papel de agente em Luis corta el jamón, ao passo que em golpearon a Luís exerce a função sintática de complemento direto e a função semântica de paciente.

Com relação à sua denominação, a explicação para a inadequação do termo circunstancial, assim como da sua classificação, encontra-se na sua própria origem. De acordo com Masiá Canuto (1994), o conceito de complemento circunstancial foi introduzido na gramática escolar francesa em 1844 por Prosper Poitevin. O termo circunstancial vem motivado, por um lado, pela retórica, da qual tomou sua denominação e características fundamentais e, por outro, da 
tradição gramatical logicista do século XVIII, que associa o termo circunstancial ao advérbio que, por sua vez, está relacionado a conceitos acessórios ou acidentais da oração. Desse modo, os complementos circunstanciais são comumente classificados como uma palavra ou um grupo de palavras, geralmente identificados como advérbios ou locuções adverbiais (de tempo, lugar, companhia, modo, instrumento, causa, finalidade) que não são exigidos pela grade argumental do verbo75 e que, portanto, podem ser prescindíveis. De modo geral, a ideia de que esses complementos cumprem um papel marginal na oração é predominante, pois se constata que, em muitos casos, constituem elementos que podem ser suprimidos sem nenhuma perda para a estrutura do enunciado, devido à sua relativa independência semântica e à sua maior mobilidade na sequência oracional. Esses são alguns dos critérios utilizados por Gómez Torrego (2002) para a caracterização formal dos complementos circunstanciais:

\begin{abstract}
El complemento circunstancial propiamente dicho se puede eliminar sin que se resienta la gramaticalidad de la oración, aunque se pierda información. Recuérdese que se trata de un complemento no argumental del verbo. Ejemplo: Aquel día caminaba yo alegremente por el campo con mis alumnos. Esta oración se puede quedar en Caminaba yo. Los complementos circunstanciales suelen permitir una movilidad en la oración mayor que la de otros complementos. Ejemplo: En casa todos leemos el periódico - Todos leemos en casa el periódico. Todos en casa leemos el periódico. - Todos leemos el periódico en casa. (GÓMEZ TORREGO, 2002, p. 31176)
\end{abstract}

Alarcos Llorach (2008, p. 366) comenta que a própria designação de circunstanciais alude a adjacentes cujos conteúdos marginais são acrescentados

\footnotetext{
75 Utilizado especialmente pela gramática gerativa, o termo grade ou estrutura argumental se aplica aos elementos selecionados pelo predicado. As escolas gramaticais, em sua maioria, fazem a distinção entre argumentos ou constituintes nucleares, exigidos pelo núcleo verbal, e adjuntos ou constituintes periféricos, que não são exigidos pelo verbo. Para Gómez Torrego (2002, p. 297), argumentos e adjuntos constituem dois tipos de complemento do verbo. São argumentos o complemento direto, o complemento indireto, o complemento preposicionado ou regido e alguns complementos adverbiais (circunstanciais).

76 "O complemento circunstancial propriamente dito pode ser eliminado sem comprometimento da gramaticalidade da oração, apesar da perda de informação. Vale recordar que se trata de um complemento não argumental do verbo. Exemplo: Aquele dia caminhava alegremente pelo campo com meus alunos. Essa oração pode reduzir-se a Caminhava. Os complementos circunstanciais costumam permitir uma maior mobilidade na oração em comparação com outros complementos. Exemplo: Em casa todos lemos o jornal. Todos lemos em casa o jornal. Todos em casa lemos o jornal. Todos lemos o jornal em casa."
} 
aos já expressados pelo núcleo verbal e seus objetos. Provavelmente, ao advertir a inadequação do termo original, cuja definição tradicional fundamenta-se em grande parte em critérios semânticos e não funcionais, chamou-os de aditamentos:

\begin{abstract}
Consideramos aditamentos los segmentos de una oración cuya presencia o ausencia no afecta a la estructura esencial de aquélla, y que además gozan de cierta movilidad de situación. Son elementos relativamente marginales, que añaden, adicionan algo al contenido global manifestado, sin perturbar la estrutura de la oración ni la de sus elementos esenciales, o sea, el sujeto y el predicado. (ALARCOS LLORACH, 1970, p. 220-22177)
\end{abstract}

De modo geral, nos manuais de gramática, prevalece a definição do complemento circunstancial identificado como a palavra ou conjunto de palavras que expressam diversas circunstâncias que, por sua natureza ou conteúdo semântico, determinam e modificam o significado verbal. De um modo ou de outro, de forma implícita ou não, a classe dos advérbios aparece como a categoria mais representativa dos complementos circunstanciais, posto que estes, da mesma forma que os advérbios, remetem a conceitos de tempo, lugar, modo, conteúdo etc. Semelhante interpretação pode ser encontrada, por exemplo, em Gili Gaya (1980), para quem os complementos verbais ${ }^{78}$, além de delimitarem a extensão do significado da ação verbal, contribuem para a fixação do seu conteúdo representativo, isto é, determinam de forma mais precisa os valores semânticos expressados pelo verbo. Nesse sentido, os advérbios expressam conteúdos qualitativos e quantitativos da ação do verbo e designam ordinariamente qualidades do verbo "do mesmo tipo que as expressadas pelos complementos circunstanciais" (GILI GAYA, 1980, p. 103-104).

\footnotetext{
77 "Consideramos aditamentos os segmentos de uma oração cuja presença ou ausência não afeta a estrutura essencial daquela e que, além disso, gozam de certa mobilidade de situação. São elementos relativamente marginais, que acrescentam, adicionam algo ao conteúdo global manifestado, sem perturbar a estrutura da oração nem a dos seus elementos essenciais, ou seja, o sujeito e o predicado."

78 Gili Gaya (1980) denomina complementos a todas as palavras ou elementos que completam a predicação quando o verbo, por si só, não é suficiente para expressar tudo o que se quer dizer do sujeito. Assim, dá-se a predicação completa em El niño duerme e predicação incompleta em $E l$ niño duerme en la cuna (GILI GAYA, 1980, p. 67).
} 
Complementos circunstanciales son los que expresan el lugar, modo, tiempo, medio, causa o instrumento de la acción verbal. Ejemplos: Desde mi casa veo la torre de la iglesia; Cumpliré de buena gana el encargo de usted; En aquellos años no se había inventado el ferrocarril; Escribiré con la pluma nueva. En estas oraciones los complementos circunstanciales son respectivamente: desde mi casa (lugar); de buena gana (modo); en aquellos años (tiempo); con la pluma nueva (instrumento). En latín se expresaban en ablativo, y en castellano suelen llevar alguna de las preposiciones con, de, desde, en, hacia, hasta, por, sin, sobre, tras etc., y algunas veces o y para con significación muy distinta de la que les corresponde en el acusativo y dativo. (GILI GAYA, 1980, p. 6779)

Na mesma linha, o Esbozo da Real Academia Espanhola (2005) chama complemento circunstancial ao vocábulo que denota circunstâncias de modo, lugar, tempo, causa, meio ou instrumento da ação verbal. E, dentre as três formas mais usuais elencadas para expressar essas circunstâncias, na oração simples, figuram em primeiro plano os advérbios ou locuções adverbiais:

a) Adverbios o locuciones adverbiales: Enrique llegará mañana; Se expresaba difícilmente, He cumplido de buena gana el encargo de usted; Trabajaban a regañadientes.

b) Sustantivos o frases sustantivas introducidos por alguna de las preposiciones bajo, com, de, desde, en, hacia, hasta, por, sin, sobre, tras, etc; p. ej.: Desde mi casa veo la torre de la iglesia; Escribo con la pluma nueva; Vienen de Galicia; Por motivos de salud no puedo asistir a la junta. También las preposiciones a y para pueden expresar relaciones circunstanciales; p. ej.: Estaba sentado al sol; El barco saldrá para Montevideo.

c) Frases de significado temporal o cuantitativo, sin preposición alguna, v. gr.: Estuve dos meses en Sevilla; Anduvo siete días a pie; Pasó toda su vida adulando a los poderosos; He contado el dinero veinte veces; Llovió el día entero. (RAE, 2005, p. 375-37680)

79 "Complementos circunstanciais são os que expressam o lugar, tempo, modo, causa ou instrumento da oração verbal. Exemplos: Da minha casa vejo a torre da igreja; Cumprirei de bom grado a sua tarefa; Naqueles anos não tinham inventado o trem; Escreverei com caneta nova. Nessas orações, os complementos circunstanciais são, respectivamente: da minha casa (lugar); de bom grado (modo); naqueles anos (tempo); com caneta nova (instrumento). Em latim se expressavam em ablativo, e em castelhano costumam construir-se com algumas das preposições: com, de, desde, em, para, até, por, sobre, detrás etc, e algumas vezes ou e para com significação muito diferente da que lhes corresponde no acusativo e dativo.”

80 "a) advérbios ou locuções adverbiais: Enrique chegará amanhã ; Expressava-se dificilmente, Eu cumpri a tarefa de bom grado para o senhor; Eles trabalhavam à força. b) substantivos ou frases nominais introduzidas por uma das preposições sob, com, de, desde, em, para, até, por, sem, sobre, detrás etc.; p.ex.: Da minha casa vejo a torre da igreja; Eu escrevo com a nova caneta; Eles vêm de Galícia; Por motivos de saúde não posso assistir à reunião. Também as preposições a e para podem expressar relações circunstanciais; p.ex.: Eu estava sentado ao sol; O navio partirá para Montevidéu. c) Frases de significado temporal ou quantitativo sem 


\section{A pretendida identidade funcional entre adjacente adverbial e complemento circunstancial}

Em razão da estreita relação entre funções e categorias, constata-se, de modo geral, que as funções de sujeito, complemento direto e indireto correspondem ao sintagma nominal, os complementos do nome ao sintagma adjetival etc. Assim, tradicionalmente, tem se estabelecido uma correspondência unívoca entre funções e categorias, na medida em que se designa uma função a uma só categoria que a representa, o que acarreta a consideração de que os complementos circunstanciais estão adscritos à categoria dos advérbios de forma exclusiva.

A explicação para a tese tradicional de que o complemento circunstancial assume uma função adverbial também vem fomentada pela identidade funcional entre advérbios e adjacentes adverbiais, posto que o advérbio situa-se como a única categoria que cumpre as funções próprias dos adjacentes adverbiais de forma autônoma, isto é, não precisa de capacitadores funcionais como preposições ou conjunções: muy tarde, más despacio. A propósito da função gramatical exercida pelo advérbio, Alarcos Llorach (1970) observa que a gramática acadêmica não apresenta de forma clara qual é a função do advérbio na oração, limitando-se à explicação semântica das relações que estabelece com outros termos, tais como as de qualificar e determinar o verbo, o adjetivo e outro advérbio e, sobre o emprego do termo advérbio, assinala:

\footnotetext{
Para que llamemos adverbios a determinadas unidades, es necesario que en la oración exista una función en la que ellas solas puedan actuar autónomamente, es decir, sin requerir la presencia de otros signos que indiquen tal función. Si se mantiene el término "adverbio" como designación de una clase funcional de unidades, sólo podrá aplicarse a aquéllas que cumplan estas condiciones: ser signos mínimos y cumplir sin la adjunción de índices funcionales la función que hemos llamado de aditamento. Otras secuencias no mínimas pueden actuar como aditamento, pero ya no pueden llamarse adverbios, puesto que están constituídas de varios elementos: unos, que pueden ser autónomos en
}

nenhuma preposição, p.ex.: Estive dois meses em Sevilha; Ele andou sete dias a pé; Ele passou toda a sua vida adulando os poderosos; Eu contei o dinheiro vinte vezes; Choveu o dia inteiro." 
otras funciones, otros cuyo papel es indicar precisamente la función de aditamento. (ALARCOS LLORACH, 1970, p. 220 ${ }^{81}$ )

Por outro lado, a simbiose funcional entre advérbios e adjacentes adverbiais conduz, consequentemente, à consideração de que todo segmento não adverbial que funciona como circunstancial passa por uma transcategorização prévia ou, dito de outro modo, deve necessariamente adverbializar-se (GUTIÉRREZ ORDÓÑEZ, 2002). Esta mesma ideia vem corroborada, por exemplo, em Gili Gaya (1980), principalmente quando se trata das relações de lugar, tempo e modo:

Los complementos circunstanciales que expresan relaciones de lugar, tiempo y modo equivalen a los adverbios. Andar con facilidad expresa lo mismo que andar fácilmente; el sustantivo mañana en la oración ha llegado esta mañana, pasa a ser adverbio en mañana llegará. Así ha ocurrido que muchos adverbios son antiguos substantivos adverbializados por hallarse frecuentemente usados en complementos circunstanciales; y así se han formado también numerosas frases adverbiales con preposición y substantivo, como de golpe, de vez en cuando, a bulto, al revés, en el acto, en efecto, en resumen, en fin etc. etc. (GILI GAYA, 1980, p. 210 ${ }^{82}$ )

Pela definição anterior, depreende-se que os complementos circunstanciais admitem comutação por um advérbio. No entanto, Gutiérrez Ordóñez (1991, p. 23) aponta uma série de complementos circunstanciais como

\footnotetext{
81 "Para que possamos chamar de advérbios a determinadas unidades, é necessário que na oração exista uma função na que elas sozinhas possam atuar de forma autônoma, isto é, sem requerer a presença de outros signos que indiquem tal função. Se mantivermos o termo advérbio como designação de uma classe funcional de unidades, somente poderá aplicar-se a aquelas que cumpram estas condições: ser signos mínimos e cumprir sem a adjunção de índices funcionais a função que chamamos de aditamento. Outras sequências que não são mínimas podem atuar como aditamento, mas já não podem se chamar de advérbios, posto que são constituídas de vários elementos: uns que podem ser autônomos em outras funções, outros cujo papel é indicar precisamente a função de aditamento."

82 "Os complementos circunstanciais expressam relações de lugar, tempo e modo equivalentes aos advérbios. Andar com facilidade expressa o mesmo que andar facilmente; o substantivo mañana na oração ha llegado esta mañana, passa a ser advérbio em mañana llegará. Isso já aconteceu com muitos advérbios que são na verdade substantivos adverbializados por serem frequentemente utilizados como complementos circunstanciais; e assim também fizeram várias locuções adverbiais com preposição e substantivo como de golpe, de vez em quando, a granel, ao revés, no ato, com efeito, em resumo, enfim etc." Com relação ao exemplo citado pelo autor, mañana llegará, é preciso esclarecer que, na língua espanhola, a mesma palavra mañana se emprega tanto para o substantivo como também para o advérbio, ao contrário do ocorre em português, que possui a palavra manhã como substantivo em Chegou nesta manhã e a palavra amanhã como advérbio em amanhã chegará.
} 
os de causa, fim, instrumento, matéria, companhia etc., que não obedecem a esse critério:

Fue derrotada por su falta de concentración

La llamaron para firmar

La interpretó con un piano de cola

Salió con su novio

Anda sin una peseta

Hacían las casas de adobe

(GUTIÉRREZ ORDÓÑEZ, 1991, p. 2383)

Com respeito aos sintagmas preposicionados anteriores, o autor observa que existem abundantes exemplos de complementos circunstanciais com valor temporal que são representados pelo par substantivo + preposição e afirma que não há nenhum obstáculo para sustentar que o complemento circunstancial, ou aditamento, seja na verdade uma função aberta às categorias adverbial e nominal. (GUTIÉRREZ ORDÓÑEZ, 1991, p. 443)

De forma análoga, para Álvarez Martínez (1992), o advérbio deve agruparse aos substantivos e adjetivos, integrando o grupo dos nomes, em oposição ao verbo, e critica a antiga tradição gramatical de incluir o advérbio, de forma sistemática, no grupo das unidades indeclináveis ${ }^{84}$ ou invariáveis como a preposição e a conjunção. A autora enfatiza a pouca atenção dada à função sintática desempenhada pelo advérbio, além do fato de que este último sempre esteve relacionado com o complemento circunstancial, o que também contribuiu

83 "Foi derrotada pela sua falta de concentração. Chamaram-na para assinar o documento. Fez a interpretação com um piano de cauda. Saiu com seu namorado. Anda sem um real. Faziam as casas de barro batido."

${ }^{84} \mathrm{~A}$ autora faz referência às reminiscências das declinações e casos latinos nos nomes em castelhano. Os substantivos, adjetivos e pronomes são nomes declináveis, isto é, pertencem a declinações ou grupos que têm desinências ou terminações próprias para os casos (nominativo, genitivo, ablativo). O substantivo luna é declinável, já que, em latim, pertence à primeira declinação, cuja terminação do nominativo singular é lun- $a$ e no plural é lun-ae. Em castelhano, o advérbio, a preposição e a conjunção são indeclináveis, pois carecem de desinências ou morfemas indicadores de gênero e número. 
para que ficasse relegado a um segundo plano devido às suas conotações de termo acessório da oração. Isso ocorreu devido ao protagonismo dado ao agente da ação verbal, em detrimento de outros complementos da oração, considerados elementos marginais, o que prejudicou a classificação do advérbio e dos complementos circunstanciais e, consequentemente, das orações adverbiais. (ÁLVAREZ MARTÍNEZ, 1992, p. 287)

Álvarez Martínez sustenta que, à usança do substantivo, o adjetivo ou verbo, o advérbio assume uma função nuclear ou constante em determinadas construções como horas antes de partir, días más tarde, callejón arriba, cuesta abajo etc. Assim sendo, nos segmentos dos horas antes e cuesta abajo, os adjacentes seriam nominais e pertenceriam à categoria substantiva; já em más tarde ou poco después, os adjacentes, nominais, pertenceriam à categoria adverbial (ÁLVAREZ MARTÍNEZ, 1992, p. 288).

\section{Um complemento circunstancial, mas nem tanto}

A consideração de que o advérbio assume uma função nominal deixa aberto o caminho para a interpretação de que também pode ser empregado para outras funções nominais tais como suplemento (complemento regido) ou atributo. Alarcos Llorach (1970) observa que, com muita frequência, os aditamentos que aparecem constituídos de sintagmas nominais precedidos de preposições ( $a$, con, de, en, por...) podem confundir-se com outros adjacentes com as mesmas características formais, porém não têm função de aditamento, posto que, ao contrário deste, sua elisão modifica, sim, a estrutura do predicado. Assim, a referência funcional de alguns adjacentes permite a comutação por zero em hablaba de noche > hablaba entonces, hablaba de corrido > hablaba así, ao passo que é obrigatória em contextos como hablan de política > hablan de ella, hablaba del tiempo > hablaba de él. A estes sintagmas preposicionais requeridos pelo predicado verbal, o autor designou o termo suplemento (ALARCOS LLORACH, 1970, p. 117-118). A questão radica em que nem sempre é fácil 
deslindar as fronteiras entre o que se pode ou não eliminar da estrutura oracional do ponto de vista semântico. Para Rojo (1990, p. 158), a aplicação automática do critério de eliminação sem alteração da estrutura oracional possui sérias limitações, já que induz a interpretar como marginais outros elementos nucleares da cláusula como o complemento direto ou indireto:

Estuvo leyendo un libro

Estuvo leyendo

Regaló flores a sua abuela

Regaló flores

(ROJO, 1990, p. 16085)

Do mesmo modo, Rojo (1990, p. 158) observa que, por um lado, há suplementos passíveis de eliminação com determinados verbos: hablar de algo ${ }^{86}$, retractarse de algo, pensar en algo e, por outro lado, há aditamentos cuja eliminação daria como resultado uma cláusula agramatical como em residir en, sacar algo de algún sitio etc.). $\mathrm{O}$ autor comenta que o problema estriba em equiparar marginalidade com possibilidade de eliminação, pois o fato de que um elemento possa ser eliminado, em determinado contexto, não determina que ele seja, necessariamente, um elemento marginal (ROJO, 1990, p. 161). Para tentar resolver essas questões, Rojo parte da teoria de Simon Dik para a distinção dos elementos da cláusula entre argumentos (elementos nucleares) e satélites (elementos marginais) na medida em que o caráter de argumento ou satélite não vem definido por um único elemento apenas, mas por todo o esquema sintático da cláusula, assim como o caráter do predicado em questão. A importância de dar prioridade aos esquemas sintáticos sobre as funções permite considerar que en Vigo seja satélite em hemos comprado uma casa en Vigo e argumento em residen en Vigo. Com vistas a corrigir os inconvenientes do teste eliminatório, Rojo utiliza

${ }_{13}$ "Leu um livro. Leu. Deu flores à sua avó. Deu flores." 86 Embora em menor grau, o suplemento em falar de algo está mais propenso à supressão que em aspirar a algo ou contar com algo.

86 Embora em menor grau, o suplemento em falar de algo está mais propenso à supressão que em aspirar a algo ou contar com algo. 
a chamada prova de Happ, que consiste em usar proformas hacer, hacerlo ou hacer lo mismo cujos elementos compatíveis são marginais. Assim, nos exemplos que seguem, en el jardín constitui um elemento marginal em

Juan estuvo leyendo un libro en el jardín

Lo hizo en el jardín

Juan estuvo leyendo un libro en el jardín y Pedro lo hizo en su habitación (ROJO, 1990, p. 16287)

Em contrapartida, são nucleares aqueles elementos que não admitem a coaparição com a proforma:

Juan estuvo leyendo una novela.

Juan estuvo leyendo una novela y Pedro hizo lo mismo.

${ }^{*}$ Lo hizo una novela. ${ }^{88}$

Mis amigos residieron en Vigo.

*Lo hicieron en Vigo. 89

Puso el libro en la estantería.

*Lo hizo en la estantería. 90

(ROJO, 1990, p. 161)

Embora reconheça o valor central dos complementos das estruturas anteriores, Rojo apresenta restrições para considerar o complemento de reside en Vigo como suplemento, dentre outras razões, porque permite a comutação por advérbio, reside ali, e porque a preposição não está regida pelo verbo: residen en/cerca de/junto a/al lado de... Vendo a necessidade de reconhecer sua função

\footnotetext{
87 “João leu um livro no jardim. Ele o fez no jardim. João leu um livro no jardim e Pedro o fez no seu quarto."

88 "João leu uma novela. João leu uma novela e Pedro fez o mesmo. *Ele o fez uma novela."

89 "Meus amigos residiram em Vigo. *Eles o fizeram em Vigo."

90 "Pôs o livro na estante. *Ele o fez na estante."
} 
na cláusula, propõe que sejam denominados provisoriamente de complementos adverbiais (ROJO, 1990, p. 166).

Não obstante, Gutiérrez Ordóñez (1995, p. 445) observa que alguns advérbios permitem suplementos adverbiais: hablaba de allí, se acuerda mucho de entonces, assim como os advérbios de lugar e tempo aparecem comutados e coordenados com um substantivo:

\section{Viene de París y Madrid > Cerca de París y Madrid \\ Viene de ahí y de París > Cerca de ahí y de París}

(GUTIÉRREZ ORDÓÑEZ, 1995, p. 44391)

Gutiérrez Ordóñez (1995) toma como único critério relevante o caráter de maior ou menor marginalidade [+-marginalidade] para simplificar a questão sobre suplementos, aditamentos e complementos adverbiais, de modo que atribui a função de suplemento (S) aos complementos que Rojo considera complementos adverbiais (CA) nas orações seguintes:

Se acuerda de allí

Se acuerda de entonces

Reside en Vigo

Proviene de allí

Precede de entonces

(GUTIÉRREZ ORDÓÑEZ, 1995, p. 44592)

Se partirmos do princípio de que tanto suplementos como aditamentos cumprem uma função nominal e levarmos em conta o critério de [+marginalidade] como o único válido para distinguir funções, encontramos uma explicação bastante razoável para delimitar a função dos complementos quando estes vêm representados por advérbios locativos e temporais: vivió entonces,

91 "Vem de Paris e Madri. > Vem daí e de Paris. Perto de Paris e Madri. > Perto daí e de Paris." 92 "Lembra-se dali. Lembra-se de então. Reside em Vigo. Provém dali. Precede de então." 
reside aquí. Gutiérrez Ordóñez (1995, p. 444), seguindo a ideia original proposta por Alarcos Llorach (1970), defende que esse tipo de advérbios locativos espaçotemporais são, em realidade, substantivos genéricos ou pronomes e que, portanto, podem exercer, nesse caso, a função de suplemento: está en Lisboa > está allí. Assim como o pronome, possuem um extenso conteúdo arquilexemático que lhes permite substituir substantivos (ou adjetivos) que estejam dentro do seu campo designativo: allí $>$ [+N] + dêixis de terceira pessoa + lugar onde [+L.unde]. Dito de outro modo, advérbios como aqui, ahí e allí incluem, nos seus significados, os valores de lugar onde, incorporando, assim, o mesmo conteúdo significativo que denotam as preposições en, sobre, bajo, ante, so, tras, motivo pelo qual estas podem ser dispensadas. Obedece, pois, a uma questão formal a existência de suplementos sem preposição como residen allí, pon el libro allí, já que a proforma alli é incompatível com preposições que indiquem lugar onde: *Vive en aquí > Vive aqui. A partir da interpretação de que os advérbios de lugar e tempo apresentam comportamento equivalente às formas pronominais, Gutiérrez Ordóñez (2002) propõe que o aditamento assume funções sintáticas nominais como as representadas no quadro abaixo:

Quadro 1 - Funções do aditamento

\begin{tabular}{|c|c|c|}
\hline Funciones & Expresión nominal & Expresión pronominal \\
\hline Compañía & Sale con los amigos & Sale con ellos \\
\hline Causa & Lo hace por compasión & Lo hace por eso \\
\hline Fin & Se priva para adelgazar & Se priva para eso \\
\hline Beneficiario & Compró piso para Pepe & Compró para él \\
\hline Materia & La hizo de barro & La hizo de eso \\
\hline Medio & Lo envió por su hijo & Lo envió por él \\
\hline Instrumento & Opera con un bisturí & Opera con eso \\
\hline Privación & Llegó sin el Abrigo & Llegó sin eso \\
\hline Agente & Detenido por la policía & Detenido por ella \\
\hline
\end{tabular}




\begin{tabular}{|c|c|c|}
\hline Lugar de... donde & Viene de Madrid & Viene de allí \\
\hline Lugar hacia donde & Va hacia Madrid & Va hacia allí \\
\hline Lugar por donde & Pasa por su finca & Pasa por allí \\
\hline Tiempo desde cuando & Lo sabe desde el lunes & Lo sabe desde entonces \\
\hline Tiempo hasta cuando & Estará hasta el 2005 & Estará hasta entonces \\
\hline
\end{tabular}

Fonte: GUTIÉRREZ ORDÓÑEZ, 2002, p. $13^{293}$.

\section{O complemento circunstancial e a oração subordinada}

A problemática classificação do complemento circunstancial, derivada da tendência tradicional em relacioná-lo ao advérbio, estende-se, por tabela, à classificação das chamadas orações adverbiais. Isso ocorre, fundamentalmente, porque se parte do princípio equivocado de que existe uma correspondência unilateral entre funções e categorias. Como consequência, a consideração de que o advérbio é o representante mais prototípico do complemento circunstancial induziu ao estabelecimento de que toda oração de circunstancial tem que ser adverbial, posto que, de acordo com a tradição gramatical, as orações subordinadas desempenham funções sintáticas, que estão equiparadas ao mesmo nível de categorias como o nome ou sintagma nominal. Como reflexo desse princípio, a classificação das orações subordinadas se baseia no estabelecimento de paralelismos onde o tipo de sintagma determina a oração subordinada que cumpre sua função, de maneira que ao sintagma nominal corresponde uma oração substantiva, ao sintagma adjetival, uma oração adjetiva e ao sintagma

\footnotetext{
$93 \mathrm{O}$ quadro apresenta as seguintes funções, seguidas por expressão nominal e expressão pronominal. Companhia: Sai com os amigos. Sai com eles; Causa: Faz isso por compaixão. Faz por isso; Fim: Priva-se para emagrecer. Priva-se para isso; Beneficiário: Comprou apartamento para Pepe. Comprou para ele; Matéria: Fez de barro. Fez disso; Meio: Enviou-o por seu filho. Enviou por ele; Instrumento: Opera com um bisturi. Opera com isso; Privação: Chegou sem o casaco. Chegou sem isso; Agente: Detido pela polícia. Detido por ela; Lugar de onde: Vem de Madri. Vem daí; Lugar para onde: Vai para Madri. Vai para lá; Lugar por onde: Passa pela sua fazenda. Passa por lá; Tempo desde quando: Sabe desde segunda. Sabe desde então; Tempo até quando: Estará até 2005. Estará até então.
} 
adverbial, uma oração subordinada adverbial (GUTIÉRREZ ORDÓÑEZ, 2002, p. 119).

Em Samuel Gili Gaya (1980) temos uma perfeita explicação acerca da correspondência entre as funções das classes de palavras e as orações subordinadas:

\begin{abstract}
En la oración simple $E l$ nin $\square$ o fugitivo recordo' entonces su abandono, podemos sustituir fugitivo por que huía; entonces por cuando estuvo lejos; y su abandono por que se hallaba abandonado. En este caso habremos formulado nuestro pensamiento por medio de un perí odo subordinado constituido por tres oraciones dependientes del verbo principal: el nin $\square$ o que hui a recordó, cuando estuvo lejos, que se hallaba abandonado. La primera representa a un concepto adjetivo (fugitivo); es subordinada adjetiva. La segunda sustituye a un adverbio (entonces); es subordinada adverbial. La tercera expresa lo mismo que un substantivo (su abandono); es subordinada substantiva. Dentro de este marco caben todas las oraciones subordinadas. (GILI GAYA, 1980, p. 285-28694)
\end{abstract}

À semelhança do que aconteceu em relação ao par complemento circunstancial / advérbio, alguns autores perceberam que é incoerente, do mesmo modo, chamar de adverbiais as orações subordinadas que não possuem correspondência com o advérbio, o que, por sua vez, provocou o surgimento de outras denominações variantes. Assim, Gómez Torrego (2007) divide as orações subordinadas circunstanciais em circunstanciais adverbiais e não adverbiais. As circunstanciais adverbiais desempenham as funções próprias do advérbio com o qual podem comutar:

\author{
Fuimos adónde nos habíais dicho > Fuimos allí. \\ Marta bucea como nos han explicado > Marta bucea así. \\ (GÓMEZ TORREGO, 200795)
}

\begin{abstract}
94 "Na oração simples o menino fugitivo lembrou então do seu abandono, podemos substituir fugitivo por que fugia; então por quando estava longe; e seu abandono por que se achava abandonado. Nesse caso, teremos formulado nosso pensamento por meio de um período subordinado constituído por três orações dependentes do verbo principal: o menino que fugia lembrou, quando estava longe, que estava abandonado. A primeira representa um conceito adjetivo (fugitivo); é subordinada adjetiva. A segunda substitui um advérbio (então); é subordinada adverbial. A terceira expressa o mesmo que um substantivo (seu abandono); é subordinada substantiva. Dentro desse quadro cabem todas as orações subordinadas."

95 "Fomos aonde nos disseram > Fomos ali. Marta mergulha como nos explicaram > Marta
\end{abstract}


De forma contrária, as circunstanciais não-adverbiais não equivalem a advérbios nem admitem ser substituídas por eles:

Fuimos a Madrid para estar con vosotros $>$ Fuimos.

Si termino mis estudios, me iré a París > Me iré a París.

Marta bucea porque le gusta > Marta bucea.

(GÓMEZ TORREGO, 2007, p. 23296)

A troca da denominação tradicional de orações subordinadas para subordinadas circunstanciais aparece no Esbozo de 1973, que divide as subordinadas hipotáticas em três grupos oracionais: substantivas, que incluem as orações de sujeito, complemento direto e complemento nominal (substantivo ou adjetivo); adjetivas (especificativas e explicativas) e circunstanciais, que abrangem um amplo e heterogêneo conjunto de orações que, por diferentes procedimentos formais, expressam as circunstâncias de lugar, tempo, modo, comparação, finalidade, causa, consequência, condição e concessão (REAL ACADEMIA ESPAÑOLA, 2005, p. 504).

Não obstante, Gutiérrez Ordóñez (2002, p. 121) adverte que a troca do termo adverbiais por circunstanciais não foi afortunada, pois incorre em uma contradição com respeito ao modo de classificar as outras orações subordinadas, segundo pode ser observado pela correspondência defectiva entre o tipo de sintagma e a oração que equivale à sua respectiva função:

$\begin{array}{lll}\text { - Sintagma nominal } & > & \text { Oraciones subordinadas sustantivas } \\ \text { - Sintagma adjetival } & > & \text { Oraciones subordinadas adjetivas } \\ \text { - Sintagma adverbial } & > & \varnothing \\ \text { - Función C. Circunstancial } & > & \text { Oraciones subordinadas circunstanciales }\end{array}$

(GUTIÉRREZ ORDÓÑEZ, 2002, p. 12197)

mergulha assim."

96 "Fomos a Madri para estar com vocês > Fomos. Se terminar meus estudos, irei a Paris > Irei a Paris. Marta mergulha porque gosta > Marta mergulha."

97 "Sintagma nominal > orações subordinadas substantivas. Sintagma adjetival > orações 
O próprio Esbozo da RAE reconhece que há incongruência na escolha da metodologia empregada para a classificação das chamadas circunstanciais, na medida em que afirma que sua classificação não é nem lógica, nem fechada na sua totalidade, porque nela estão encobertos, de certa forma, os critérios que permitem a diferenciação dos grupos das subordinadas, o que tenta justificar alegando que o sistema linguístico não opera a partir de conceitos lógicos e totalmente delimitáveis:

Como es natural, esta clasificación [...] no constituye un todo lógico cerrado cuyos términos se excluyan sin residuo, porque superpone tres criterios de distinción de los diferentes grupos de subordinadas: en primer lugar, la función gramatical que desempeñan; después, la naturaleza del nexo; y, finalmente, el significado total del período como unidad lingüística. Ya es sabido que la lengua constituye un sistema congruente en la sincronía y apto para la expresión de cada comunidad parlante; pero no es nunca un sistema de conceptos exclusivamente lógicos que puedan delimitarse con nitidez completa. Por esto nuestra clasificación debe tomarse como una guía aproximada para penetrar en la estructura movediza del habla oral y escrita. (REAL ACADEMIA ESPAÑOLA, 2005, p. 51498)

Alarcos Llorach (2008, p. 447) observa que a classificação tradicional das orações transpostas adverbiais não tem em conta sua estrutura interna; pelo contrário, baseia-se numa interpretação semântica que remete a conteúdos que equivalem a advérbios de tempo, lugar, modo, causa, finalidade etc. A diversidade de valores atribuídos a essas orações degradadas depende de um conjunto de fatores léxicos e gramaticais que variam segundo a configuração assumida pela oração. Nesse sentido, foram denominadas como adverbiais próprias aquelas estruturas oracionais transpostas que funcionalmente admitem substituição por

subordinadas adjetivas. Sintagma adverbial $>$ Ø. Função C. circunstancial $>$ orações subordinadas circunstanciais.”

98 "Como é natural, essa classificação [...] não constitui um todo lógico fechado cujos termos se excluem sem resíduo, porque superpõe três critérios de distinção dos diferentes grupos de subordinadas: em primeiro lugar, a função gramatical que desempenham; em segundo lugar, a natureza do nexo; e, finalmente, o significado total do período como unidade linguística. Já é sabido que a língua constitui um sistema congruente na sincronia e apto para a expressão de cada comunidade de falantes; mas não é nunca um sistema de conceitos exclusivamente lógicos que podem ser delimitados com nitidez completa. Por isso, nossa classificação deve ser tomada como uma guia aproximada para penetrar na estrutura movediça da fala oral e escrita." 
um advérbio, ao contrário das adverbiais impróprias, que não admitem tal comutação. As adverbiais próprias se restringem às temporais, locativas e modais e costumam cumprir a função de adjacentes circunstanciais do núcleo oracional:

Puso el cuadro donde había más luz. > Puso el cuadro allí.

Tratadlo como se merece. > Tratadlo así.

(ALARCOS LLORACH, 2008, p. 44799)

Como não existem advérbios que denotem valores de causa, fim, concessão e condição, as adverbiais impróprias vêm representadas por grupos nominais que assumem a função circunstancial própria do advérbio:

Lo haré porque me conviene.

$>$ Lo haré por mi conveniencia.

Me voy para que se tranquilicen.

$>$ Me voy para su tranquilidad.

Si tuviera éxito, me alegraría.

$>$ En caso de éxito, me alegraría.

Aunque esté cansado no debe cejar.

$>$ Con todo su cansancio, no debe cejar.

(ALARCOS LLORACH, 2008, p. 447 ${ }^{100}$ )

A Nova Gramática da Real Academia Espanhola (REAL ACADEMIA, 2009) admite que, em relação a outros tipos de subordinação, cuja estrutura interna pode ser identificada com mais facilidade, o conceito de subordinação adverbial é polêmico na atualidade, posto que, por exemplo, as subordinadas adverbiais tradicionais podem vir representadas por gerúndio como em se

99 "Pôs o quadro onde tinha mais luz > Pôs o quadro ali. Tratem-no como merece > Tratem-no assim."

100 "Eu o farei porque me convém. > Eu o farei para minha conveniência. Estou saindo para que se tranquilizem. $>$ Estou partindo para sua tranquilidade. Se eu tivesse sucesso, eu me alegraria. $>$ Em caso de sucesso, eu me alegraria. Mesmo que você estiver cansado, não deve desistir. > Com todo o seu cansaço, não deve desistir." 
progresa esforzándose. Além disso, aponta três problemas que derivam da noção tradicional de subordinação adverbial. O primeiro consiste na inexatidão do paralelismo com os advérbios dos que toma a sua denominação, já que não existem advérbios que possam substituir as orações finais, causais, concessivas etc. Do mesmo modo, é inadequado utilizar o termo circunstancial para as prótases das condicionais e concessivas, pois estas não são circunstanciais. $\mathrm{O}$ segundo problema diz respeito ao conceito de subordinação adverbial, que se confunde com outras classificações oracionais. Assim, no caso das relativas sem antecedente expresso, cujo nexo relativo seja um advérbio, existe a possibilidade de que a oração subordinada relativa seja reinterpretada por uma oração subordinada adverbial, como ocorre, por exemplo, em o livro está onde te disse, que também permite a comutação por ali. O terceiro problema advém do fato de que muitos gramáticos consideram inadequado classificar como oração ao segundo segmento de orações como, por exemplo, a condicional si Julia llama que consta de dois segmentos [si] [Julia llama], o que consistiria em uma redundância, tendo em conta que o termo oração também se atribui à estrutura formada pelos dois segmentos. A mesma divisão binária é utilizada para construções similares precedidas por conjunções ou locuções conjuntivas subordinantes, que possuem uma estreita relação com as subordinadas adverbiais (REAL ACADEMIA ESPAÑOLA, 2009, p. 77, 1.13q).

Outrossim, não fica descartada a utilização, embora restringida, do termo subordinação adverbial quando se julgue necessário fazer referência aos conteúdos expressados por essas orações na tradição gramatical hispânica. Para evitar os diversos problemas surgidos da análise detalhada da noção de subordinação adverbial, emprega o termo construção, o qual reconhece ser deliberadamente vago para a descrição simplificada das propriedades dos tipos oracionais (REAL ACADEMIA, 2009, p. 78, 1.13u).

Para tentar resolver todas as questões que envolvem a problemática classificação e delimitação das funções atribuídas às subordinadas adverbiais, Gutiérrez Ordóñez (2002) propõe a mesma solução discutida anteriormente para os complementos adverbiais / circunstanciais, isto é, considerar que os 
aditamentos (complementos circunstanciais) podem ser sintagmas nominais ou adverbiais. Da mesma forma, é preciso considerar que determinados advérbios locativos e temporais são, na realidade, proformas pronominais que equivalem, portanto, a sintagmas nominais. De acordo com esse princípio, já não haveria necessidade de estabelecer distinções entre subordinadas adverbiais próprias e impróprias, tampouco entre subordinadas circunstanciais adverbiais e não adverbiais, posto que, na qualidade de sintagmas nominais, podem ser incluídas no grupo das subordinadas substantivas com a função de aditamento. Portanto, são consideradas subordinadas substantivas tanto as orações do grupo I (circunstanciais / adverbiais próprias) como as do grupo II (circunstanciais / adverbiais impróprias) (GUTIÉRREZ ORDÓÑEZ, 2002, p. 120-121):

I - Adverbiais próprias

Viaja desde cuando era niño

Viaja hasta que se cansa

Viaja donde se divierte

Viaja cuando está de vacaciones

II - Adverbiais impróprias

Viaja para que se diviertan sus hijos

Viaja porque lo necesita

Viaja con quienes quiere

Viaja con lo que le gusta

(GUTIÉRREZ ORDÓÑEZ, 2002 ${ }^{101}$ )

\footnotetext{
101 "Viaja desde quando era criança. Viaja até se cansar. Viaja onde se diverte. Viaja quando está de férias. Viaja para que os filhos se divirtam. Viaja porque necessita. Viaja com aqueles que ama. Viaja com o que gosta.”
} 


\section{Considerações Finais}

Como síntese das ideias tratadas anteriormente neste trabalho, constatamos que a polêmica suscitada pelo chamado complemento circunstancial radica em duas questões fundamentais que envolvem, por um lado, os diversos problemas que derivam da sua classificação, baseada essencialmente em critérios semânticos e não funcionais e, por outro, o conhecido critério de eliminação, sem comprometer a estrutura oracional, ordinariamente utilizado na identificação desse complemento, bem como da sua diferenciação do suplemento.

Desde o seu surgimento, uma longa tradição gramatical tem relacionado o complemento circunstancial a elementos ou partes acessórias do predicado oracional. Devido à tendência de estabelecer de forma unilateral correspondências entre funções e categorias, o complemento circunstancial ficou identificado com categoria dos advérbios e, como tal, passou a empregar-se para construções que expressam os valores de tempo, lugar, modo, instrumento, companhia etc. No entanto, há diversas evidências que revelam a inconsistência dessa associação, sobretudo pela existência de complementos circunstanciais representados por sintagmas nominais precedidos de preposição, os quais não admitem a substituição por um advérbio. A equivocada equivalência entre subordinada adverbial e advérbio, decorrente da tradição gramatical de classificar as orações subordinadas em substantivas, adjetivas e adverbiais, é resultado da premissa errônea de que as categorias ou classes de palavras como substantivo, adjetivo e advérbio desempenham sempre as mesmas funções sintáticas.

No que concerne ao caráter prescindível do complemento circunstancial, comprova-se, do mesmo modo, que há vários exemplos de casos que fogem a essa regra. Rojo (1999) demonstra que o critério de eliminação sem alteração da estrutura oracional mostra-se bastante limitado, na medida em que compromete outros elementos centrais da oração tais como o complemento direto e indireto, 
além de não contemplar determinados aditamentos cuja elisão redunda em uma oração agramatical como em *reside en. Nesse sentido, vale notar a advertência do autor para o fato de que nem todo elemento passível de eliminação da oração constitui um elemento marginal e ressalta a importância de priorizar os esquemas sintáticos na sua totalidade, ao invés de deduzir funções a partir de um único elemento, pois, a depender da configuração sintática que tomam os elementos da oração e do significado léxico do predicado verbal, um mesmo elemento pode ser central como em residen en Vigo ou marginal como em compramos uma casa en Vigo. Sobre outros casos que provocam mais dúvidas sobre a sua função, como suplemento ou aditamento, parece válido utilizar a prova de Happ proposta por Rojo, além do critério de maior ou menor grau de marginalidade com respeito ao núcleo verbal.

Para a delimitação mais adequada da função exercida pelo complemento circunstancial (aditamento), consideramos viável a proposta de Gutiérrez Ordóñez (1991 e 2002) de lhe atribuir uma função nominal. Para o caso dos complementos com advérbios locativos e temporais como viven allí ou puso el libro allí, Gutiérrez Ordóñez (2002) demonstra que, na verdade, tratam-se de elementos que atuam como proformas pronominais equivalentes a sintagmas nominais: viven en Galicia; puso el libro en el estante. Similarmente, os complementos circunstanciais que denotam conteúdos como os de companhia, causa ou instrumento, podem vir representados por uma expressão nominal e outra pronominal, respectivamente: sale con amigos > sale con ellos; hace por compasión > hace por eso; opera con un bisturi > opera con eso. A consideração de que o complemento circunstancial assume uma função preponderantemente nominal torna, pois, desnecessária a incoerente classificação e divisão entre complemento circunstancial /adverbial e orações subordinadas circunstanciais / adverbiais (próprias e impróprias), fruto da sua clássica associação com os adjacentes adverbiais. Como consequência dessa nova interpretação, chega-se à conclusão lógica de que o verdadeiro lugar das chamadas subordinadas adverbiais (próprias e impróprias) pode estar no grupo das orações subordinadas substantivas. 
Por último, vale notar que este trabalho pretendeu contribuir com as discussões e análises realizadas por linguistas e gramáticos que, a partir de diferentes enfoques teóricos, têm procurado oferecer possíveis soluções à problemática classificação do complemento circunstancial e da oração subordinada adverbial, temas dos mais controvertidos no contexto da linguística hispânica, ao longo dos últimos anos. Nesse sentido, espera-se que outras pesquisas se sucedam a esta e que possam somar-se às propostas concretas de Rojo (1999) e Gutiérrez Ordóñez (1991 e 2002) no tocante a outras questões gramaticais que interferem no complexo quadro da subordinação adverbial. 


\section{Referências}

ALARCOS LLORACH, Emilio. Gramática de la lengua española. Real Academia Española, Colección Nebrija y Bello. 17 ed. Madrid: Espasa Calpe, 2008.

ALARCOS LLORACH, Emilio. Estudios de gramática funcional del español. Madrid: Gredos, 1970.

ÁLVAREZ MARTÍNEZ. María Ángeles. Aspectos históricos del funcionamiento del adverbio español. Actas del II Congreso Internacional de Historia de la Lengua Española. Tomo I, Madrid, Pabellón de España, 1992, p. 283-290. Disponível em: http://www.cervantesvirtual.com/nd/ark:/59851/bmc93163. Acesso em: 14 mai. 2020.

BOSQUE, Ignacio; GUTIÉRREZ-REXACH, Javier. Fundamentos de sintaxis formal. Madrid: Ediciones Akal, 2009.

FERNÁNDEZ LÓPEZ, Justo. Los complementos circunstanciales. Gramática española - nivel superior. Hispanoteca - Lengua y cultura hispanas. Disponível em:

http://hispanoteca.eu/Gram\%C3\%A1ticas/GRAM\%C3\%81TICA\%20ESPA\%C3 \%91OLA.htm. Acesso em: 14 mai. 2020.

GILI GAYA. Samuel. Curso superior de sintaxis española. 13. ed. Barcelona: Vox, 1980.

GÓMEZ TORREGO. Leonardo. Gramática didáctica del español, 8. ed. Madrid: SM, 2002.

GÓMEZ TORREGO. Leonardo. Análisis sintáctico. Teoría y práctica. Madrid: SM. 2. ed. 2007.

GUTIÉRREZ ORDÓÑEZ, Salvador. “¿Hablamos del suplemento?”. Scripta Philologica in Memoriam Manuel Taboada Cid, Universidad de La Coruña, 1995, p. 434-451. Disponível em:

http://www.gruposincom.es/salvadorgutierrez/hablamos\%20del\%2osuplemen to.pdf. Acesso em: 14 mai. 2020.

GUTIÉRREZ ORDÓÑEZ. Salvador. Forma y sentido en sintaxis. Madrid: Arco Libros, 2002.

GUTIÉRREZ ORDÓÑEZ. Salvador. La transposición sintáctica (Problemas). Lecciones de Lingüística y Didáctica del Español 10. Logroño. Consejería de 
Educación, Cultura y Deportes de la Comunidad de La Rioja, 1991. Disponível em:

http://www.gruposincom.es/salvadorgutierrez/la\%20transposicion\%20sintacti ca.pdf. Acesso em: 14 mai. 2020.

MASIÁ CANUTO, María Luísa. El complemento circunstancial en español. Castelló de la Plana: Publicaciones de la Universitat Jaume I, 1994.

REAL ACADEMIA ESPAÑOLA. Esbozo de una nueva gramática de la lengua española. 22 ed. Madrid: Espasa Calpe, 2005.

REAL ACADEMIA ESPAÑOLA. Nueva Gramática de la lengua española. 2 Vol. Madrid: Espasa Libros, S.A, 2009.

ROJO, Guillermo. Sobre los complementos adverbiales. Homenaje al profesor Francisco Marsa'. Universidad de Barcelona, Barcelona, 1990, p. 153-171.

Artigo recebido em 15 de maio de 2020 e aceito em 23 de junho de 2020. 